\title{
FTIR and thermal studies on esters grafted HDPE
}

\author{
Vellaichamy Parthasarathy ${ }^{a}$, Viswalingam Dhanalakshm ${ }^{b}$ and Ramasamy Anbarasan ${ }^{b^{*}}$
}

\begin{tabular}{|c|c|}
\hline$\overline{C H R O N}$ I C LE & A B S T R A C T \\
\hline $\begin{array}{l}\text { Article history: } \\
\text { Received January 26, } 2013 \\
\text { Received in Revised form } \\
\text { May 10, } 2013 \\
\text { Accepted 4 June } 2013 \\
\text { Available online } \\
\text { 7 June } 2013 \\
\end{array}$ & $\begin{array}{l}\text { HDPE was functionalized with two different esters in an inert atmosphere at } 160^{\circ} \mathrm{C} \text {, under } \\
\text { different experimental conditions by thermolysis method. The order of the functionalization and } \\
\text { crosslinking reactions was determined. The } \mathrm{C}=\mathrm{C} \text { formation peak is assigned at } 1610 \mathrm{~cm}^{-1} \text {. The } \\
\text { percentage of functionalization was determined by FTIR spectroscopy method. } \\
\text { Thermogravimetric analysis and differential scanning calorimetric methods were also used to } \\
\text { study about the thermal properties of the functionalized HDPE. }\end{array}$ \\
\hline $\begin{array}{l}\text { Keywords: } \\
\text { HDPE } \\
\text { Functionalization } \\
\text { Grafting } \\
\text { FTIR } \\
\text { DSC } \\
\text { TGA } \\
\text { Crosslinking }\end{array}$ & (C) 2013 Growing Science Ltd. All rights reserved. \\
\hline
\end{tabular}

\section{Introduction}

In the recent years, the utilization of polyolefins has been increased worldwide against the increasing population. To meet our need many industries are involving in the manufacturing of polyolefins to the great extent. Billions of dollars are invested in the production of polyolefins world wide. It yields more foreign exchange. Simultaneously, problems associated with polyolefins increase due to its non-biodegradable nature. The disposal of plastic waste has become a major environmental hazard in the landfill. Among the polyolefins, one of the most important polymers is PE which has a unique status due to its excellent manufacturing property and processability. These properties can be improved by surface modifications i.e., introduction of a functional group onto the back bone of PE without environmental pollution. Grafting of Diethylmalonate and maleic anhydride onto SEBS triblock copolymer was reported by Passaglia et al. ${ }^{1}$. Functionalization of low density polyethylene

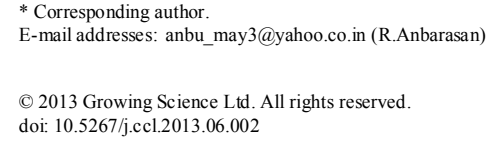


(LDPE) by melt grafting with glycidylmethacrylate was reported by Wei et al. ${ }^{2}$ and LDPE was grafted with acrylic acid ${ }^{3}$. Craig et $a l^{4}{ }^{4}$ reported UV-exposed polyolefins such as HDPE, LDPE, LLDPE etc., with improved mechanical properties. The maleic anhydride modified PP was ascertained to mix well with organo-metallic clays to form nano composites with improved thermal properties $^{5}$. During the functionalization process simultaneous crosslinking is also possible one. Below and coworkers ${ }^{6}$ reported about the electron beam cross linked PE with very high crack resistance. Grafting of undecylenic acid onto ethylene octane copolymer under molten condition was reported by $\mathrm{He}$ et al. ${ }^{7}$ Melt grafting of $\mathrm{N}$-carboxyl maleamic acid onto LLDPE was reported by Ciolino et al. ${ }^{8}$. Gaylord and Mehta et al. ${ }^{9}$ studied the melt grafting process of PE with maleic anhydride monomer. Many experimental conditions including initiator, temperature and time, etc, were studied to determine \% of cross linking and degradation that accompanies the grafting reaction ${ }^{10}$. Recently Anbarasan et al. ${ }^{11}$ studied the melt functionalization of HDPE with acrylic esters under molten condition. By thorough literature survey, we couldn't find any report based on order of $\mathrm{C}=\mathrm{C}$ formation reaction for EM and EAA ester functionalized HDPE in the presence of DCP, under inert condition at $160^{\circ} \mathrm{C}$.

\section{Experimental}

\subsection{Materials}

High density polyethylene (HDPE) was purchased from Ottokemi, India. In order to remove the antioxidant present in the HDPE sample, it was purified prior to thermolysis reaction. The purification procedure was explained in our earlier publication ${ }^{12}$ Dicumyl peroxide (DCP, Ottokemi, India), 1,2dichloro benzene (AR, Loba Chemi, India), Diethylmalonate (EM, CDH, India) and Ethylacetoacetate (EAA, Ottochemi, Inida), Dichloromethane (AR, Merck, India), Acetone (AR, Paxmy, India) and Toluene (Loba Chemi, India) were used without subjecting them to any other purification process.

\subsection{Thermolysis reaction}

Melt graft functionalization of HDPE with EM and EAA was carried out through thermolysis reaction. The short procedure is illustrated further. Previously purified HDPE was taken in a $25 \mathrm{ml}$ round-bottom flask along with the required amount of ester and equal quantity of DCP were taken in a solution of $6 \mathrm{ml}$ of dichloromethane $(9 \mathrm{ml}) /$ cyclohexane $(1 \mathrm{ml})$ mixture. The contents were mixed for $2.5 \mathrm{~h}$ at room temperature. After this mixing process, the solvents had been removed with the help of a rotavapour under reduced pressure until a constant mass was obtained. The polymer/peroxide/ester mixture thus obtained was taken in a test tube reactor. The reactor was closed and degassed by the injection of sulphur free nitrogen gas for $30 \mathrm{~min}$ and then sealed. The reactor was heated in an oil bath at $160^{\circ} \mathrm{C}$ for $2.5 \mathrm{~h}$ without any stirring. When the reactants melted, the reaction started and led to various processes such as surface graft functionalization, alkenes formation and crosslinking reactions. Then the products were cut into small pieces and dissolved in DCB at $120^{\circ} \mathrm{C}$ for $2 \mathrm{~h}$. During this dissolution process, the non-crosslinked (ester functionalization part is soluble in DCB solvent whereas the crosslinked polymer is insoluble in DCB. $500 \mathrm{ml}$ of acetone was added to precipitate the soluble and functionalized HDPE. The ester functionalized samples were weighed and stored in a zipper bag.

\subsection{Characterization}

FTIR spectra of HDPE samples in the form of film before and after peroxide treatment were recorded, using Shimadzu 8400 S FTIR spectrophotometer instrument. For FTIR film preparation, the soluble part of the modified HDPE was alone considered. Then the spectrum was recorded. The baseline correction was made carefully and the area of the peaks was determined using FTIR software. For the 
quantitative determination of percentage grafting, the area of the peak at 1730 and $720 \mathrm{~cm}^{-1}$ was determined and relative intensity was calculated as follows:

$$
\begin{aligned}
& \begin{array}{c}
\text { Relative intensity of carbonyl }(\mathrm{RI})=\mathrm{A}_{1730} / \mathrm{A}_{720} \\
\text { Relative intensity of } \mathrm{C}=\mathrm{C}(\mathrm{RI})=\mathrm{A}_{1604} / \mathrm{A}_{720}
\end{array} \\
& \% \mathrm{Cster} \text { grafting }=\frac{\mathrm{RI}[\mathrm{C}=\mathrm{O} / \mathrm{C}-\mathrm{H}] \times \mathrm{W}}{\mathrm{C} \times 1.52} \times 100 \\
& \mathrm{C} \times \mathrm{C} \text { formation }=\frac{\mathrm{RI}[\mathrm{C}=\mathrm{C} / \mathrm{C}-\mathrm{H}] \times \mathrm{W}}{2.35} \times 100
\end{aligned}
$$

where, $\mathrm{W}$ is the weight of non-cross linked polymer, $\mathrm{C}$ is the \% weight of peroxide and 1.52 and 0.35 are calibration coefficients taken from our earlier publication ${ }^{13}$. DSC was recorded for the samples by using SDT 2960 simultaneous TGA and DSC, TA instruments under Nitrogen atmosphere at the heating rate of $10^{\circ} \mathrm{C} / \mathrm{min}$. The TGA analysis was performed under air purge at the heating rate of $10^{\circ} \mathrm{C} / \mathrm{min}$ by using the SDT 2960 simultaneous TGA and DSC, TA instruments. The \% crosslinking was determined by using the following formula:

$\%$ crosslinking $=\frac{[\text { Weight of Polymer taken for functionalization]-[Weight of non-crosslinked polymer obtained after functionalization] }}{\text { Weight of Polymer taken for functionalization }} \times 100$

\section{Results and Discussion}

In the functionalization of HDPE, two types of esters such as EM and EAA were used. Equal \% weight of DCP and esters were used. Functionalization reaction was carried out under different experimental conditions like variation in (\% weight of DCP), different temperature and different intervals of time.

\subsection{FTIR Characterization}

The FTIR spectra of functionalized HDPE with different \% weight of EM are shown in Fig 1. Important peaks are discussed below: Peaks between 2600 and $3000 \mathrm{~cm}^{-1}$ are related with the $\mathrm{C}-\mathrm{H}$ stretching vibrations. The stretching of $-\mathrm{C}=\mathrm{O}$ - could be seen at $1723 \mathrm{~cm}^{-1}$. The $\mathrm{C}-\mathrm{H}$ bending vibration is observed at $1490 \mathrm{~cm}^{-1}$. A sharp peak at $730 \mathrm{~cm}^{-1}$ is associated with the $\mathrm{C}-\mathrm{H}$ deformations. The new peak, which appeared at the wave number of $1050 \mathrm{~cm}^{-1}$, is used to confirm the $\mathrm{C}-\mathrm{O}-\mathrm{C}$ ester linkage. The $\mathrm{C}=\mathrm{C}$ formation peak is assigned at $1610 \mathrm{~cm}^{-1}$. The remaining peaks correspond to pure HDPE. Fig. 2 illustrated the FTIR spectra of EAA functionalized HDPE under different \% weight of EAA. In this system also, the above-mentioned peaks were observed. The FTIR spectra of EM and EAA functionalized HDPE under different temperature and time interval is not shown here.

\subsection{Effect of (\% weight of DCP) on \% functionalization, $\%$ crosslinking and $C=C$ formation}

The \% weight ratio of DCP and EM was used in equal concentrations. In the present study, the \% weight of EM varied between 3 and 7 . The \% of ester grafting was increased with the increase of (\% weight of DCP). This is in accordance with our earlier publication ${ }^{13}$. The reason for this may be due to the availability of more and more free radicals, derived from DCP for grafting of EM onto HDPE. The order of functionalization reaction was determined from log-log plot which was made between $\log (\%$ weight of DCP) and $\log \left(\mathrm{RI}_{[\mathrm{C}=\mathrm{O} / \mathrm{C}-\mathrm{H}]}\right)$. Fig. 3(a) represented the same with a straight line. 


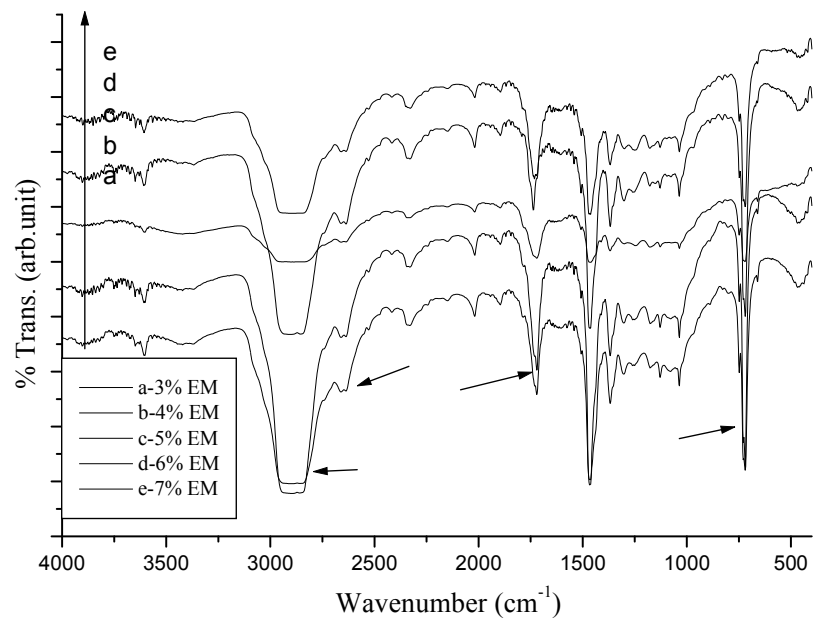

Fig. 1. FTIR spectrum of EM functionalized HDPE under different \% weight of EM

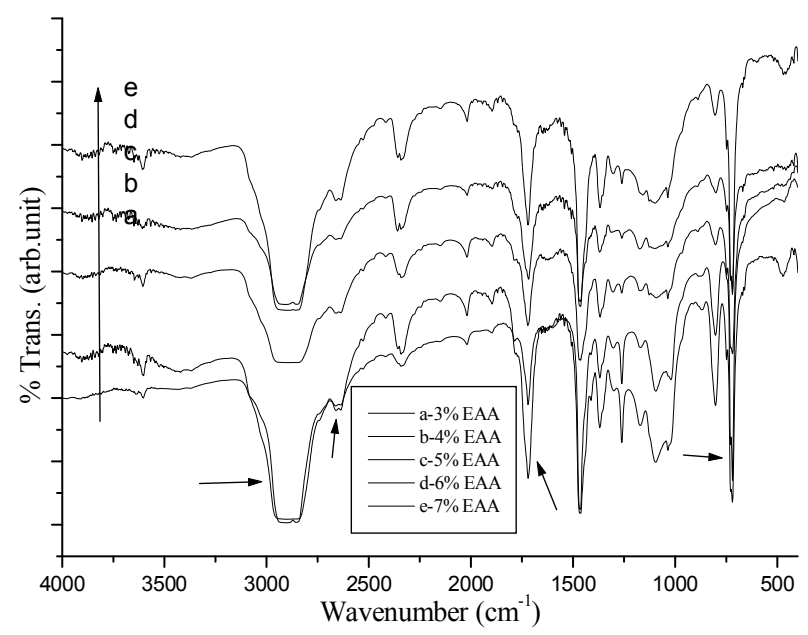

Fig. 2. FTIR spectrum of EAA functionalized HDPE under different \% weight of EAA

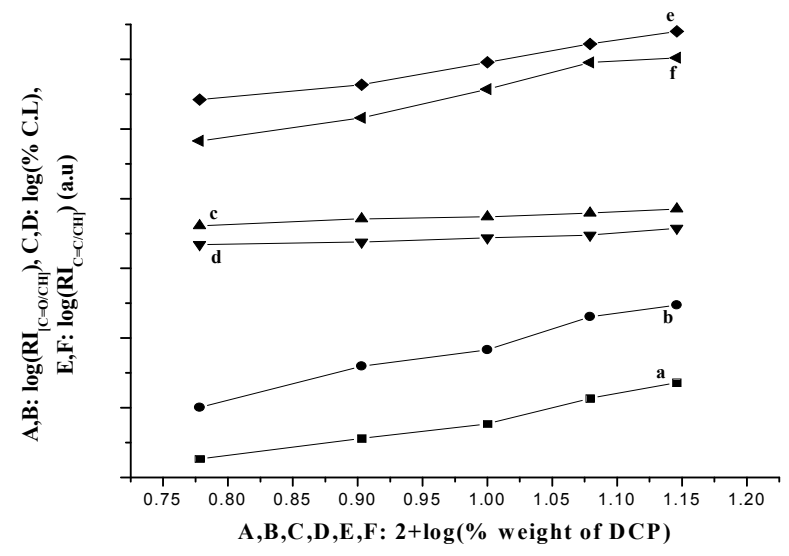

Fig. 3. Effect of (\% weight of DCP) on ( $a$ and $b)\left(R I_{[C=O / C-H]}\right)$, (c and $\left.d\right)\left(\%\right.$ C.L), (e and f) $\left(R I_{[C=C / C-H]}\right)$ of (a, $c$ and e) HDPE-DCP-EM and (b, $d$ and f) HDPE-DCP-EAA systems. Time- $2 \mathrm{~h}$, Temperature- $160^{\circ}$ $\mathrm{C}$, Weight of HDPE-2.0 $\mathrm{g}$ 
The slope value was determined as 1.56 , which confirmed the 1.50 order of functionalization reaction with respect to (\% weight of DCP). The rate of functionalization reaction $\left(\mathrm{R}_{\mathrm{f}}\right)$ can be written as follows: $\mathrm{R}_{\mathrm{f}} \alpha(\% \text { weight of DCP })^{1.50}$. This explained that $1.50 \mathrm{~mol}$ of DCP is required to functionalize one mole of HDPE. Similar type of plot was made for EAA system as shown in Fig. 3(b). It shows a straight line which proved increase in RI of carbonyl ester. Here the slope value was determined as 1.30. This confirmed 1.25 order of functionalization reaction with respect to (\% weight of DCP). The rate of functionalization revealed that 1.25 mole of DCP is required to functionalize one mole of HDPE for EAA system. The \% grafting values are listed in Table 1. During the functionalization reaction, crosslinking reaction and $\mathrm{C}=\mathrm{C}$ formation reactions were competitive. The efficiency of crosslinking was analyzed kinetically for both EM and EAA systems. In order to find the order of crosslinking reaction, a log-log plot was made between $\log (\%$ weight of DCP) and $\log (\%$ crosslinking) as shown in Fig. 3(c). The slope value was determined as 0.26 which inferred that 0.25 order of crosslinking reaction with respect to (\% weight of DCP). For EAA system, the slope value was found to be 0.25 from Fig. 3(d). This confirmed the 0.25 order of crosslinking reaction with respect to ( $\%$ weight of DCP). The $\%$ crosslinking was dominant than that of $\%$ functionalization because of the vigorous coupling nature of HDPE macro radicals. The rate of crosslinking reaction $\left(\mathrm{R}_{\mathrm{C} . \mathrm{L}}\right)$ can be written as follows: $\mathrm{R}_{\mathrm{C} . \mathrm{L}} \alpha(\%$ weight of DCP $)^{0.25}$ for both systems. It means that $0.25 \mathrm{~mol}$ of DCP is required to crosslink one mole of HDPE for both EM and EAA. Another possible reaction is $\mathrm{C}=\mathrm{C}$ formation during the melt functionalization reaction. This formation was confirmed by the presence of Peak at $1610 \mathrm{~cm}^{-1}$. This happened due to the oxidative thermal degradation reaction. Fig. 3(e) represented the plot of $\log (\%$ weight of DCP) vs $\log \left(\mathrm{RI}_{[\mathrm{C}=\mathrm{C} / / \mathrm{C}-\mathrm{H}]}\right)$ for EM grafted HDPE system. While increasing the (\% weight of $\mathrm{DCP})$, the $\%$ of $\mathrm{C}=\mathrm{C}$ formation was increased. One recent publication indicated the melt surface grafting of succinimide with HDPE in the presence of DCP, we found that while increasing the \% weight of SI, the $\% \mathrm{C}=\mathrm{C}$ formation also increased linearly ${ }^{14}$. This is in accordance with our results. The slope value was determined as 1.29 which confirmed the 1.25 order of reaction with respect to (\% weight of DCP). Similar type of plot was made for EAA grafted HDPE system as shown in Fig. 3(f) and the slope value was noted as 1.54. This confirmed the 1.50 order of double bond formation with respect to $(\%$ weight of $\mathrm{DCP})$. The rate of $\mathrm{C}=\mathrm{C}$ formation reaction $\left(\mathrm{R}_{\mathrm{D} . \mathrm{B}}\right)$ can be written as follows: $\mathrm{R}_{\mathrm{D} . \mathrm{B}} \alpha(\%$ weight of DCP $)^{1.25}$ for EM and $\mathrm{R}_{\text {D.B }} \alpha(\% \text { weight of DCP })^{1.50}$ for EAA system. It means that 1.25 mole of DCP for $\mathrm{EM}$ and 1.50 mole of DCP for EAA is required to form one mole of olefin bond in HDPE backbone for both EM and EAA. The \% crosslinking and $\mathrm{C}=\mathrm{C}$ formation values are given in Table 1.

Table 1. Effect of $(\%$ weight of $\mathrm{DCP})$ on functionalization, crosslinking and $\mathrm{C}=\mathrm{C}$ formation

\begin{tabular}{ccccccc} 
\% weight & \multicolumn{2}{c}{ \% functionalization } & \multicolumn{2}{c}{$\%$ crosslinking } & \multicolumn{2}{c}{$\% \mathrm{C}=\mathrm{C}$ formation } \\
\cline { 2 - 7 } of DCP & EM & EAA & EM & EAA & EM & EAA \\
\hline 3 & 8.06 & 24.86 & 76.5 & 68.3 & 1 & 0.98 \\
4 & 11.05 & 31.62 & 78.3 & 72 & 1.35 & 1.11 \\
5 & 14.9 & 39.98 & 81 & 74.6 & 2.71 & 1.54 \\
6 & 20.3 & 45.13 & 84.2 & 78.3 & 3.07 & 1.7 \\
7 & 22.56 & 52.92 & 89 & 81.2 & 3.24 & 1.9 \\
\hline
\end{tabular}

\subsection{Effect of temperature on $\%$ functionalization, $\%$ crosslinking and $\% C=C$ formation}

Generally \% ester grafting increased initially and then showed a decreasing trend. Beyond $160^{\circ} \mathrm{C}$, the $\%$ ester grafting was decreased. This may be due to the formation of unwanted by-products, with very high activation energy at higher temperature. The activation energy $\left(E_{a}\right)$ for functionalization of EM onto HDPE was determined from the Arrhenius plot i.e., plot of $1 / \mathrm{T}$ Vs $\log \left(\mathrm{RI}_{[\mathrm{C}=\mathrm{O} / \mathrm{C}-\mathrm{H}]}\right)$ as shown in Fig. 4(a). The slope was determined and the $E_{a}$ value was calculated as $250 \mathrm{~kJ} / \mathrm{mol}$. Similar type of plot was made for EAA system as shown in Fig. 4(b). The $E_{a}$ for functionalization of EAA onto HDPE 
was calculated as $210 \mathrm{~kJ} / \mathrm{mol}$. This revealed that EM consumed more amount of heat energy for functionalization rather than EAA. The lower $\mathrm{E}_{\mathrm{a}}$ supported higher $\%$ functionalization for EAA than EM system. The \% grafting values are presented in Table 2.

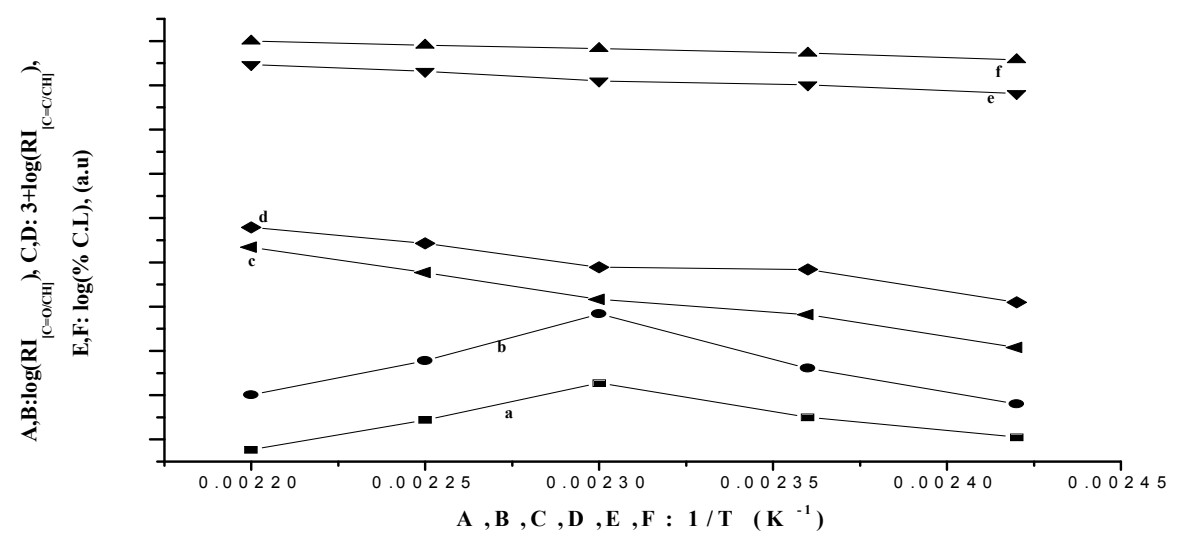

Fig. 4. Effect of temperature on (a and b) $\left(\mathrm{RI}_{[\mathrm{C}=\mathrm{O} / \mathrm{C}-\mathrm{H}]}\right)$, (c and d) $\left(\mathrm{RI}_{[\mathrm{C}=\mathrm{C} / \mathrm{C}-\mathrm{H}]}\right)(\mathrm{e}$ and $\mathrm{f})(\% \quad \mathrm{C} . \mathrm{L})$ of $(\mathrm{a}, \mathrm{c}$ and e) HDPE-DCP-EM and (b, d and f) HDPE-DCP-EAA systems. Time- $2 \mathrm{~h}, \%$ weight of DCP-5\%, Weight of HDPE-2.0 g

The effect of temperature on crosslinking of HDPE, in the presence of DCP and ester was tested. Fig. 4(c) showed the plot of $1 / \mathrm{T}$ vs $\log (\%$ crosslinking) for EM grafted HDPE system. The slope value was determined and $E_{a}$ value was found to be $152 \mathrm{~kJ} / \mathrm{mol}$. The Same type of plot was made for EAA system as given in Fig. 4(d) and the $E_{a}$ value was calculated as $170 \mathrm{~kJ} / \mathrm{mol}$. On comparison, EAA system consumed more amount of heat energy than EM. So the lower $E_{a}$ value supported higher $\%$ crosslinking for EM than EAA grafted HDPE. Effect of temperature on $\% \mathrm{C}=\mathrm{C}$ formation was analyzed for both esters. Fig. 4(e) showed the plot of $1 / \mathrm{T}$ vs $\log \left(\mathrm{RI}_{[\mathrm{C}=\mathrm{C} / \mathrm{C}-\mathrm{H}]}\right)$ for $\mathrm{EM}$ system and the $\mathrm{E}_{\mathrm{a}}$ value was found to be $110 \mathrm{~kJ} / \mathrm{mol}$. Fig. 4(f) showed the same type of plot for EAA system and the slope was calculated as $130 \mathrm{KJ} / \mathrm{mol}$. On critical comparison, one can predict that EAA consumed more amount of heat energy for the formation of $\mathrm{C}=\mathrm{C}$ than that of $\mathrm{EM}$. The $\% \mathrm{C}=\mathrm{C}$ formation was higher for $\mathrm{EM}$ than $\mathrm{EAA}$ and this was due to its lower $\mathrm{E}_{\mathrm{a}}$ value. Table 2 critically compared the $\%$ crosslinking and $\mathrm{C}=\mathrm{C}$ formation values for both esters.

Table 2. Effect of temperature on functionalization, crosslinking and $\mathrm{C}=\mathrm{C}$ formation

\begin{tabular}{ccccccc}
\multirow{2}{*}{$\begin{array}{c}\text { Temperature } \\
(\mathrm{K})\end{array}$} & \multicolumn{2}{c}{ \% functionalization } & \multicolumn{2}{c}{$\%$ crosslinking } & \multicolumn{2}{c}{$\% \mathrm{C}=\mathrm{C}$ formation } \\
\cline { 2 - 7 } & EM & EAA & EM & EAA & EM & EAA \\
\hline 413 & 11.13 & 36.48 & 67.5 & 65 & 1.88 & 0.74 \\
423 & 13.17 & 42.87 & 71.5 & 70 & 2.65 & 1.22 \\
433 & 14.9 & 55.98 & 74.3 & 73.2 & 2.71 & 1.94 \\
443 & 7.03 & 47.15 & 80.2 & 79.5 & 3.48 & 2.57 \\
453 & 3.68 & 25.11 & 87.5 & 82.4 & 4.11 & 3.34 \\
\hline
\end{tabular}

\subsection{Effect of time on \% functionalization, \% crosslinking and $\% C=C$ formation}

Grafting of esters onto HDPE in the presence of DCP was carried out at different intervals of time. Fig. 5(a) represented the effect of time on $\mathrm{RI}_{[\mathrm{C}=\mathrm{O} / \mathrm{C}-\mathrm{H}]}$ for $\mathrm{EM}$ grafted HDPE system. The plot showed a straight line and inferred that RI of carbonyl ester was increased with the increase of time. Longer intervals of reaction time lead to the possible interaction between HDPE macro radicals with EM 
radicals resulting with higher $\%$ of grafting. The same trend was noticed for the EAA system too as shown in Fig. 5(b).

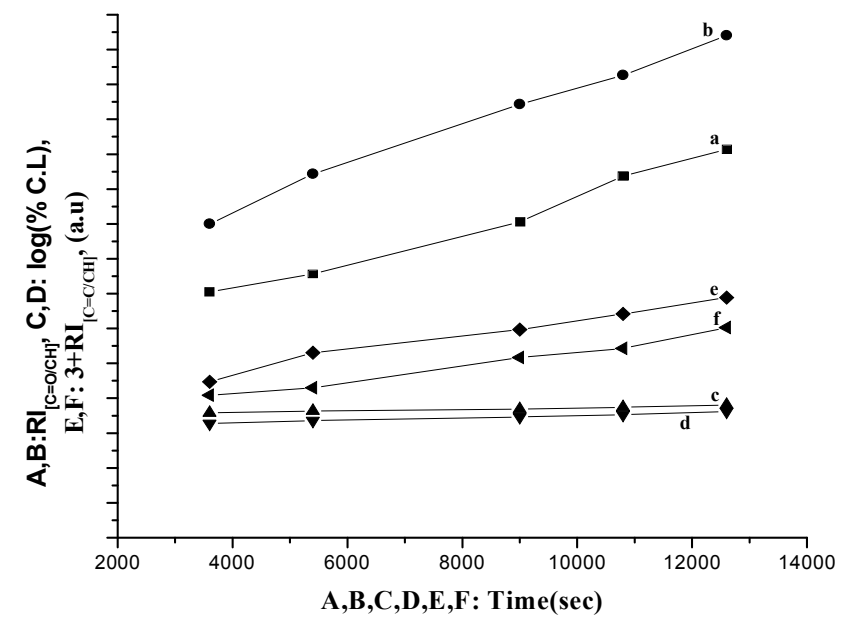

Fig. 5. Effect of time on (a and b) $\left(\mathrm{RI}_{[\mathrm{C}=\mathrm{O} / \mathrm{C}-\mathrm{H}]}\right)$, (c and d) (\% C.L), (e and f) $\left(\mathrm{RI}_{[\mathrm{C}=\mathrm{C} / \mathrm{C}-\mathrm{H}]}\right)$ of $(\mathrm{a}$, c and e) HDPE-DCP-EM and (b, $d$ and f) HDPE-DCP-EAA systems. \% weight of DCP-5\%, Weight of HDPE$2.0 \mathrm{~g}$, Temperature- $160^{\circ} \mathrm{C}$

Fig. 5(c) and (d) confirmed the increase of \% crosslinking with the increase of reaction time. This happened due to the coupling between HDPE macro radicals. Effect of time on $\mathrm{RI}_{[\mathrm{C}=\mathrm{C} / \mathrm{C}-\mathrm{H}]}$ for $\mathrm{EM}$ and EAA systems was investigated and represented in Fig. 5(e) and (f) respectively. Here also, when the reaction time is increased, the $\%$ of $\mathrm{C}=\mathrm{C}$ formation is also increased in a linear manner. This may be due to the possible thermal oxidation reaction. The $\%$ functionalization, crosslinking and $\mathrm{C}=\mathrm{C}$ formation values were mentioned in Table 3.

Table 3. Effect of time on functionalization, crosslinking and $\mathrm{C}=\mathrm{C}$ formation

\begin{tabular}{ccccccc}
\hline \multirow{2}{*}{$\begin{array}{c}\text { Time } \\
(\mathrm{sec})\end{array}$} & \multicolumn{2}{c}{ \% functionalization } & \multicolumn{2}{c}{$\%$ crosslinking } & \multicolumn{2}{c}{$\% \mathrm{C}=\mathrm{C}$ formation } \\
\cline { 2 - 7 } & EM & EAA & EM & EAA & EM & EAA \\
\hline 3600 & 6.07 & 23.01 & 72.5 & 69 & 0.97 & 1.17 \\
5400 & 6.45 & 37.9 & 77 & 73 & 1.48 & 1.37 \\
9000 & 10.06 & 45.06 & 81 & 75.5 & 2.45 & 2.34 \\
10800 & 11.08 & 52.13 & 85.5 & 79.1 & 3.17 & 3 \\
12600 & 13.59 & 57.85 & 88 & 84 & 4.08 & 3.71 \\
\hline
\end{tabular}

\subsection{DSC Profiles}

Melt functionalization of HDPE with different esters such as EM and EAA will lead to the change in physical and chemical properties of HDPE. Fig. 6 represented DSC of EM functionalized HDPE. This thermogram revealed that decrease in $\mathrm{T}_{\mathrm{m}}$ value even after the melt functionalization reaction with EM. The reasons are as follows: 1) The change in the micro structure appearance of HDPE ( $\alpha$ or $\beta$ or $\gamma$ form) slightly modifies during the melt functionalization process 2) This may be due to the chain scission of HDPE with terminal double bonds 3) Chain scission process accompanied with decrease in molecular weight which accounts for the reduction in $T_{m} 4$ ) The formation of double bond in the middle of HDPE 
chain is one of the possibilities. In the case of crystallization temperature $\left(T_{c}\right)$, much difference was not observed. But in the present investigation, nucleation due to grafted EM was not observed.

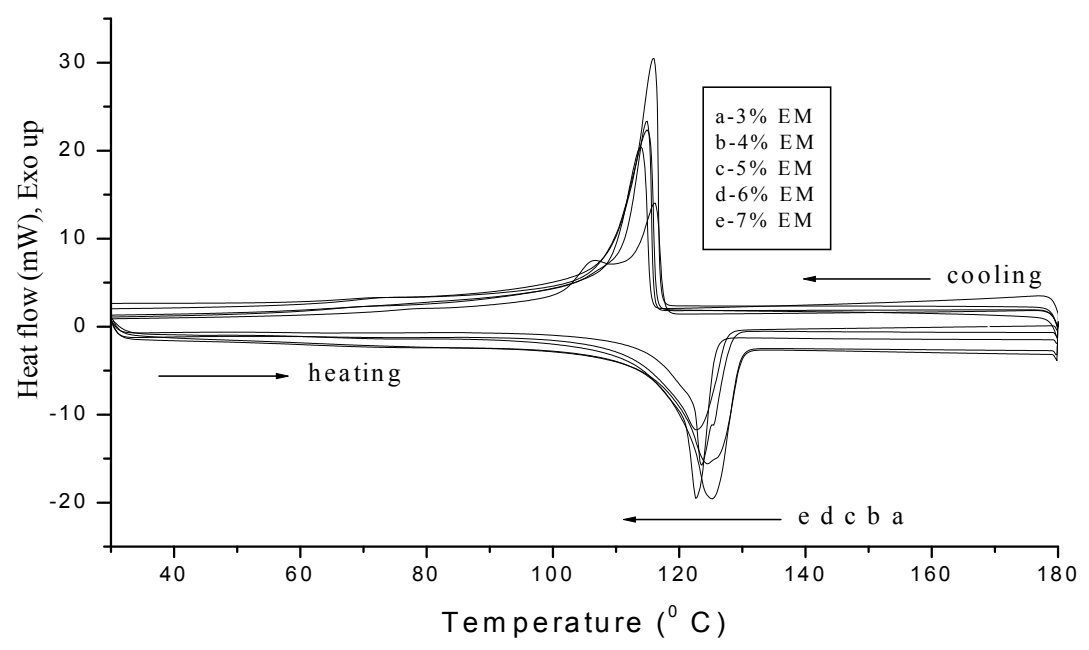

Fig. 6. DSC of EM functionalized HDPE at different \% weight of EM

Fig. 7 showed the DSC of different \% weight loading of EAA functionalized HDPE system. Here also, the $T_{m}$ value decreased while increasing the \% weight of EAA. The decrease in $T_{m}$ value was thoroughly explained by Campos and Petri ${ }^{15}$ for the tetrahydrophthalic and maleic anhydride grafted polyolefins in solution. The grafted EAA side chains had influenced the $T_{c}$ value of HDPE. This indicated that during the melt functionalization of HDPE with EAA, the crystallinity values were reduced. Further research work on GPC measurement is going on in our laboratory.

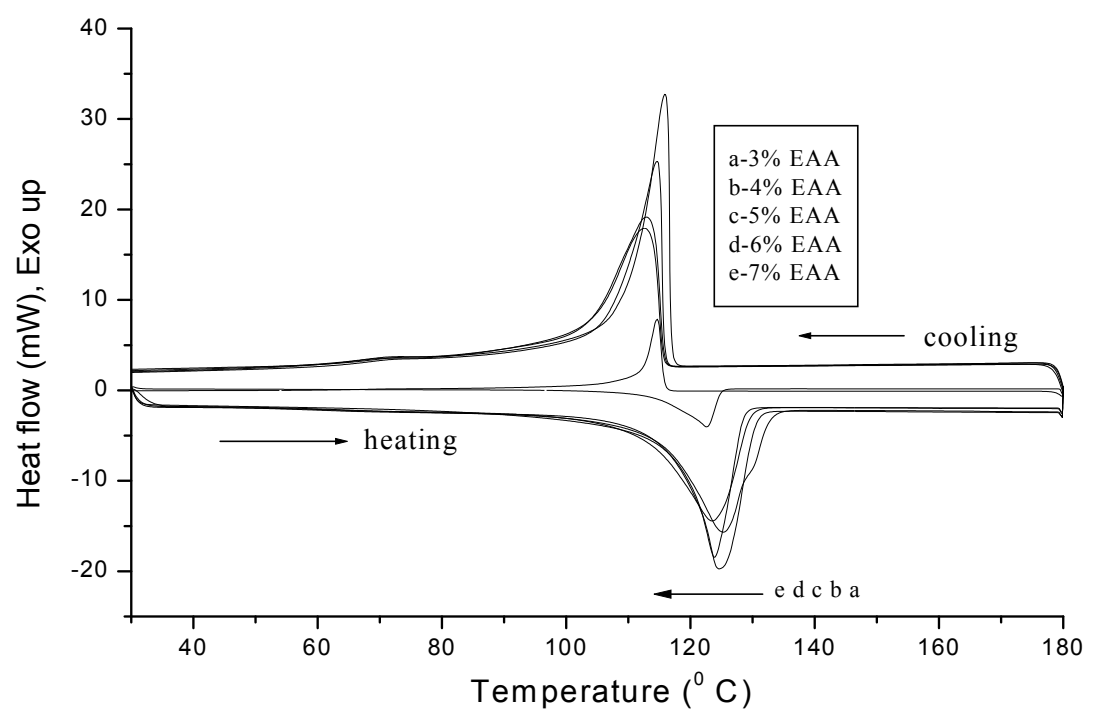

Fig. 7. DSC of EAA functionalized HDPE at different \% weight of EAA

\subsection{TGA History}

The thermal stability of functionalized HDPE was tested with the help of TGA instrument. The TGA was recorded at the heating rate of $10^{\circ} \mathrm{C} / \mathrm{min}$ under air atmosphere. The TGA of EM functionalized $\mathrm{HDPE}$ is mentioned in Fig. 8. The thermogram shows a single step degradation process. Upto $450^{\circ} \mathrm{C}$, there was no change in the structure of HDPE. The major weight loss started around $460^{\circ} \mathrm{C}$ and 
extended upto $500^{\circ} \mathrm{C}$. This accounts for the main chain scission or degradation. The important point noted here is, while increasing the \% weight of EM, the thermal stability of HDPE was slightly affected. Due to the random grafting of EM onto HDPE, the extra thermal stability due to grafted side chain was not observed. The point to be noted here is while increasing the $\%$ weight of EM the $T_{\text {id }}$ (initial degradation) is shifted towards lower temperature with slight decrease in thermal stability of ester functionalized HDPE. Girija et al. ${ }^{16}$ explained the decrease in thermal stability of LDPE functionalized with maleic ester.

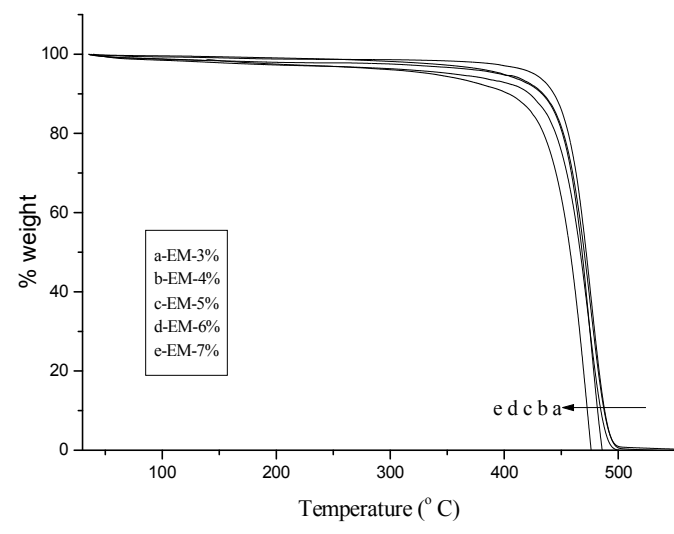

Fig. 8. TGA of EM functionalized HDPE at different \% weight of EM

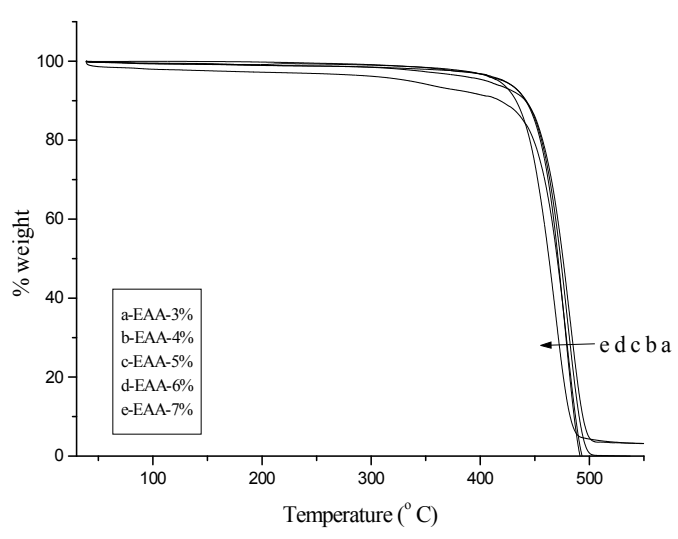

Fig. 9. TGA of EAA functionalized HDPE at different $\%$ weight of EAA

Fig. 9 showed the TGA of EAA functionalized HDPE. Here also, there was almost no change in thermal stability due to the random functionalization of EAA in the presence of DCP. Due to the random grafting of EAA onto HDPE, with very low \% of EAA used for functionalization process, the extra thermal stability due to grafted EAA was not observed. At higher \% weight of EAA, HDPE showed a considerable decrease in thermal stability. Recently, Kaith et $\mathrm{al}^{17}$ and Chauhan et $\mathrm{al}^{18-20}$ explained the thermal properties of structurally modified polymers.

\section{Conclusions}

(1) EM showed higher $\%$ crosslinking and $\mathrm{C}=\mathrm{C}$ formation than EAA. (2) The area of $\mathrm{C}=\mathrm{O}$ peak increased with increase of $\%$ ester grafting. (3) EAA showed higher $\%$ functionalization than EM (4) EM consumed less amount of heat energy for crosslinking and $\mathrm{C}=\mathrm{C}$ formation rather than EAA. (5) Ester grafting was confirmed by the presence of $\mathrm{C}=\mathrm{O}$ stretching vibration $\left(1723 \mathrm{~cm}^{-1}\right)$ and $\mathrm{C}-\mathrm{O}-\mathrm{C}$ ester linkage peak $\left(1050 \mathrm{~cm}^{-1}\right)$ (6) DSC concluded the slight decrease in $T_{m}$ and $T_{c}$ values for functionalized HDPE for both esters. (7) TGA explored the decrease in initial degradation temperature for EAA grafted HDPE system.

\section{Acknowledgements}

The author (R. Anbarasan) is thankful to the Department of Science and Technology, Government of India, New Delhi, for their financial support (Ref. No. SR/FTP/CS-39/2005).

\section{References}

1. Passaglia E., Ghett S., Ruggesi G. (2000) Grafting of diethyl maleate and maleicanhydride onto styrene-b-(ethyl-co-1-butene)-b-styrenetriblock copolymer (SEBS). Polymer, 41, 4389-4400. 
2. Wei Q., Chionna D., Pacella M. (2003) Functionalization of LDPE by melt grafting with glycidyl methacrylate and reactive blending with polyamide-6. Macromol. Chem. Phys. 204, 1123-1133.

3. Ashour A.H., Saad H.M., Ibrahim M.M. (2006) Electrical conductivity for irradiated, grafted polyethylene and grafted polyethylene with metal complex. Egypt. J. Solids., 29, 351-362.

4. Craig I.H., White J.R. (2006) Mechanical properties of photo-degraded recycled photo-degraded polyolefins. J. Mater. Sci., 41, 993-1006.

5. Chiu F.C., Chu P.H. (2006) Characterization of solution-mixed polypropylene/clay nanocomposite without compatibilizers. J. Polym. Res., 13, 73-78.

6. Below H., Quilitz W., Schunann W. (2005) Electron beam crosslinking of large diameter thick-walled polyethylene pipes. Plast. Rubber Compos., 34, 34-39.

7. He P., Huang H., Zhang Y., Liu C. (2005) Undecylenic acid grafting on ethylene-octene copolymer in molten state. React. Funct. Polym., 62, 25-29.

8. Ciolino A.E., Pieroni O.I., Vuano B.M., Villar M.A., Valles E.M. (2004) Synthesis of polybutadienegraft-poly(dimethylsiloxane) and polyethylene-graft-poly(dimethylsiloxane) copolymers with hydrosilylation reactions. J. Polym. Sci. Polym. Chem. 42, 2920-2930.

9. Gaylord N.G., Mehta M. (1982) Role of homopolymerization in the peroxide-catalyzed reaction of maleic anhydride and polyethylene in the absence of solvent. J. Polym. Sci. Polym. Lett. 20, 481486.

10. Vito G.D., Lanzetta N., Ralumbo R. (1984) Functionalization of an amorphous ethylene-propylene copolymer by free radical initiated grafting of unsaturated molecules. J. Polym. Sci. Polym. Chem. $22,1335-1347$.

11. Anbarasan R., Babout O., Dequiel M., Maillard B. (2005) Functionalization and cross-linking of high-density polyethylene in the presence of dicumyl peroxide-An FTIR study. J. Appl. Polym. Sci., 97, 766-774.

12. Parthasarathy V., Sundaresan B., Dhanalakshmi V., Anbarasan R. (2010) Functionalization and cross-linking of high-density polyethylene in the presence of dicumyl peroxide-An FTIR study. Thermochim. Acta 510, 766-774

13. Parthasarathy V., Sundaresan B., Dhanalakshmi V., Anbarasan R. (2010) Melt surface grafting of HDPE with mercaptoesters by thermolysis method. Polym. Eng. Sci., 50, 474-483.

14. Anbarasan R., Kanchana S., Gayathri S., Jayalakshmi T. (2010) Synthesis and characterizations of calcium di(meth)acrylate divinyl monomers and melt surface graft functionalization with linear low density poly(ethylene). J. Appl. Polym. Sci., 115, 2582-2590.

15. Campos P.G.S., Petri D.F.S. (2004) Grafting of tetrahydrophthalic and maleic anhydride onto polyolefins in solution. J. Braz. Chem. Soc., 15, 532-540.

16. Girija B.G., Sailaja R.R.N. (2006) Low-density polyethylene/plasticized tapioca starch blends with the low-density polyethylene functionalized with maleate ester: Mechanical and thermal properties. J. Appl. Polym. Sci., 101, 1109-1120.

17. Balbir Singh Kaith., Rajeev Jindal., Jaspreet Kaur Bhatia. (2011) Evaluation of thermal behavior of microwave induced graft copolymerization of ethylmethacrylate onto soy protein concentrate. $J$. Macromol. Sci., 48, 299-308.

18. Ashish Chauhan., Balbir Kaith. (2012) Using the advanced analytical techniques to investigating the versatile cellulosic graft copolymers. J. Anal. Bio-Anal. Tech., 3(5), 7-14.

19. Ashish Chauhan., Balbir Kaith. (2012) Versatile Sereni graft-copolymers : Xrd studies and their mechanical evaluation after use as reinforcement in composites. J. Chil. Chem. Soc., 57 (3).12621266.

20. Ashish Chauhan., Balbir Kaith. (2011) The Potential Use of Roselle as Novel Graft- copolymer. $J$. Nat. Fibers., 8(4), 308-321. 